This is the accepted version of the following article:

Martincic M., Vranic S., Pach E., Sandoval S., Ballesteros B., Kostarelos K., Tobias G.. Non-cytotoxic carbon nanocapsules synthesized via one-pot filling and end-closing of multi-walled carbon nanotubes. Carbon, (2019). 141. : 782 - .

10.1016/j.carbon.2018.10.006,

which has been published in final form at

https://dx.doi.org/10.1016/j.carbon.2018.10.006 (c) https://dx.doi.org/10.1016/j.carbon.2018.10.006. This

manuscript version is made available under the CC-BY-NC-ND

4.0 license http://creativecommons. org/licenses/by-nc-nd/4.0/ 


\section{Non-cytotoxic carbon nanocapsules synthesized via one-pot filling and end-closing of multi-walled carbon nanotubes}

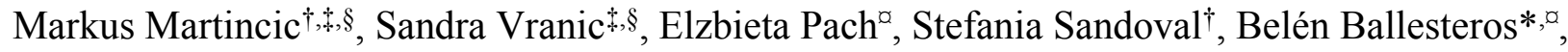

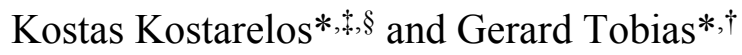

†Institut de Ciencia de Materials de Barcelona (ICMAB-CSIC), Campus de la UAB, 08193

Bellaterra, Barcelona, Spain;

$\$$ Nanomedicine Lab, Faculty of Biology, Medicine and Health, The University of Manchester, AV Hill Building, Manchester M13 9PT, U.K.;

§National Graphene Institute, The University of Manchester, Booth Street East, Manchester M13 9PL, U.K.

${ }^{\circ}$ Catalan Institute of Nanoscience and Nanotechnology (ICN2), CSIC and The Barcelona Institute of Science and Technology, Campus UAB, Bellaterra, 08193 Barcelona, Spain

*Corresponding authors.

E-mail: gerard.tobias@icmab.es (Gerard Tobias)

E-mail: belen.ballesteros@icn2.cat (Belén Ballesteros)

E-mail: kostas.kostarelos@manchester.ac.uk (Kostas Kostarelos) 


\begin{abstract}
Filled carbon nanotubes (CNTs) find application in a variety of fields that expand from sensors to supercapacitors going through targeted therapies. Bulk filling of CNTs in general results in samples that contain a large amount of non-encapsulated material external to the CNTs. The presence of external material can dominate the properties of the resulting hybrids and also induce side effects when employed in the biomedical field. Unless the encapsulated payloads have a strong interaction with the inner CNT walls, an additional step is required to block the ends of the CNTs thus allowing the selective removal of the non-encapsulated compounds while preserving the inner cargo. Herein we present a fast, easy and versatile approach that allows both filling ( $\mathrm{NaI}, \mathrm{KI}, \mathrm{BaI}_{2}, \mathrm{GdCl}_{3}$ and $\mathrm{SmCl}_{3}$ ) and end-closing of multi-walled CNTs in a single-step, forming "carbon nanocapsules". Remarkably the encapsulation of $\mathrm{GdCl}_{3}$ and $\mathrm{SmCl}_{3}$ leads to the formation of tubular van der Waals heterostructures. The prepared nanocapsules are efficiently internalized by cells without inducing cytotoxicity, thus presenting a safe tool for the delivery of therapeutic and dianostic agents to cells. The synergies of novel carbon and inorganic hybrid materials can be explored using the present approach.
\end{abstract}




\section{Introduction}

The remarkable physical properties of carbon nanotubes (CNTs) have led to much interest in their application in many diverse directions.[1-3]_ENREF_1 The presence of an inner cavity further expands the versatility of these nanomaterials allowing both their endohedral and exohedral modification. There are many examples in which the cavity of CNTs has been filled with a variety of organic and inorganic compounds, which can lead to the formation of unprecedented structures.[4-7] ENREF 5The properties of the confined materials can greatly differ from those of the same material in the bulk.[4, 7, 8]_ENREF 4 In turn, the presence of a host in the interior of CNTs allows tuning the electronic, optical and mechanical properties of the CNTs themselves.[9, 10] Filled carbon nanotubes are for instance of interest for developing sensors,[11] supercapacitors and electrode materials for lithium ion batteries.[12] The hollow cavity of CNTs can be also employed to perform reactions at the nanoscale thus allowing the synthesis of structures in a controlled manner. $[4,9,13,14]$ Due to the technological interest of 2D materials, $[15,16]$ individual layers of van der Waals solids have been synthesized by either performing chemical reactions in the cavities of CNTs, such as graphene[13, 14] and metal disulfide $\left(\mathrm{MoS}_{2}, \mathrm{WS}_{2}\right)$ nanoribbons $[17,18]$ or by direct filling, resulting in the formation of tubular van der Waals structures.[5, 7, 19, 20]

ENREF 10Among the large variety of materials that can be filled in the interior of CNTs, the encapsulation of biomedically relevant payloads has taken a great deal of attention. CNTs have been advocated as promising materials for the targeted delivery of imaging and therapeutic agents.[21-24] In this context, the carbon shell offers protection to the encapsulated cargo from the biological milieu while the external CNT walls remain available for the attachment of selected biomolecules, allowing an increase in the biocompatibility and selectivity of the 
material. Also in the biomedical field, CNTs filled with gadolinium have for instance been employed to magnetically enhance stem cell retention for cellular cardiomyoplasty[25] and for the development of multifunctional scaffolds.[26] Just from these few examples, it becomes clear that the encapsulation of materials into the cavities of carbon nanotubes opens up new possibilities to face a variety of societal challenges.

Bulk filling of carbon nanotubes is typically performed using a large amount of the selected material to be encapsulated. The excess of material that is not filled into the CNTs remains external to the walls and can dominate the properties of the resulting hybrid. Furthermore, it can lead to undesired side effects in the biological context. Having closed or corked ends, with for instance fullerenes or nanoparticles,[27-29] ensures the selective elimination of the nonencapsulated compounds while preventing the release of the inner cargo. An alternative approach consists on coating the whole surface of previously filled nanotubes with an inert protective shell, such as carbon or silica.[30-32]_ENREF 17

The permanent confinement of materials inside the cavities of carbon nanotubes is of interest when discharge of the material is not desired, forming hybrid structures that can benefit from the combined properties of carbon nanotubes and the confined compound.[33-35] Having closed ends confers stability to the system which can be beneficial in tuning the properties of the nanotubes in a stable manner, making permanent the newly acquired property. It is also of great interest for the development of nanovectors for both imaging and therapy, because as discussed, it avoids any potential toxicity from the encapsulated payload.

All the above mentioned sealing strategies require several synthetic steps because the corking/coating is performed after having filled the carbon nanotubes. From a practical point of 
view, a one-pot synthesis would be desired where the filling and sealing were achieved in a single step. This is for instance of particular importance when filling radionuclides where rapidity is a must.[36] Spontaneous closure of the ends of single-walled carbon nanotubes upon molten phase filling at temperatures above $700{ }^{\circ} \mathrm{C}-900{ }^{\circ} \mathrm{C}$ was reported back in 2006.[37] ENREF_33This resulted in the formation of closed-ended filled single-walled carbon nanotubes referred to as "carbon nanocapsules" or "nanobottles". Different biocompatible hybrid materials have been prepared in this way allowing for instance in vivo ultrasensitive imaging (filled with $\mathrm{Na}^{125} \mathrm{I}$ ),[36] cell internalization (filled with $\mathrm{SmCl}_{3}, \mathrm{LuCl}_{3}$ )[38] and even mapping of cellular organelles (filled with $\mathrm{Kr}, \mathrm{BaI}_{2}, \mathrm{PbI}_{2}$ )_ENREF_7.[39] These nanocapsules were externally functionalized in order to improve their dispersibility and biocompatibility. The developed constructs remained stable in the biological environment.

Herein we present a fast one-pot method that allows the preparation of closed-ended filled MWCNTs, which we will refer to as "multi-walled carbon nanocapsules", by molten phase capillary filling at high temperatures $\left(\mathrm{T} \geq 1000{ }^{\circ} \mathrm{C}\right)$. The main asset of the developed protocol is its simplicity in filling and sealing inorganic materials within the cavities of multi-walled carbon nanotubes. To the best of our knowledge the effect of annealing on the opened tips of MWCNTs remains to be investigated. To provide direct evidence of the efficacy and versatility of the proposed one-pot synthesis approach, a variety of multi-walled carbon nanocapsules have been prepared by filling MWCNTs with NaI, KI, $\mathrm{BaI}_{2}, \mathrm{GdCl}_{3}$ and $\mathrm{SmCl}_{3}$ (MX@MWCNTs, where X $=$ metal and $\mathrm{X}=$ halide). These are technologically relevant materials since for instance (i) potassium iodide allows tuning the electronic properties of carbon nanotubes, [10, 40] ENREF_10(ii) Gd-based compounds are widely used for magnetic resonance imaging (MRI),[41] allowing the development of multifunctional scaffolds[26] and also to magnetically 
enhance stem cell retention for cellular cardiomyoplasty[25] (iii) iodide and samarium salts are of interest for their use in nuclear medicine (using radioactive isotopes), [36, 38]_ENREF_35 (iv) the presence of heavy elements is of interest for the development of $\mathrm{x}$-ray contrast agents (Ba and I for instance)[39] and (iv) bulk $\mathrm{GdCl}_{3}$ can crystallize in the layered $\mathrm{PuBr}_{3}$ structure (van der Waals solid),[42] so it could lead to the isolation of single-layers once confined.[5, 7, 19] New properties and applications arise from the creation of van der Waals heterostructures of layered compounds.[43, 44] ENREF 44

\section{Experimental Section}

\subsection{One-pot filling and end-closing of MWCNTs}

As-received chemical vapor deposition (CVD) grown MWCNTs (Elicarb®, Thomas Swan Co. Ltd.) were initially treated with a combination of steam and acid treatments following previously reported protocols (see Supporting Information). [45] Flexible CVD MWCNTs were employed in the present study because these have been reported to present a good biocompatibility,[46] better than stiff structures.[47]

The inorganic salts, namely samarium(III) chloride, potassium iodide, sodium iodide, gadolinium(III) chloride and barium iodide (Sigma Aldrich), were handled inside a Labconco glove box with an inert argon atmosphere, with below 1 ppm of oxygen and 5 ppm of water. To fill CNTs with the given metal halide, purified carbon nanotubes (up to $100 \mathrm{mg}$ per experiment) were mixed with the chosen inorganic salt (ratio salt:CNTs, 10:1) by finely grinding them together using an agate mortar and pestle inside the glovebox. The mixture was then placed into a silica tube, which was sealed under vacuum, to around 0.05 mbar. The resulting ampoule was then placed inside a tubular furnace and annealed at temperatures in the range between 700 - 
$1300{ }^{\circ} \mathrm{C}$._ENREF 8 The program used for annealing the samples consisted of a heating ramp at $300{ }^{\circ} \mathrm{C} / \mathrm{h}$ up to the desired temperature, namely $700,1000,1100,1200$ or $1300{ }^{\circ} \mathrm{C}$, keeping this temperature for $12 \mathrm{~h}$, and cooling down at a set rate of $300{ }^{\circ} \mathrm{C} / \mathrm{h}$ until room temperature. After cooling the samples, silica tubes were cut, and the collected material was placed into a round bottom flask with $200 \mathrm{~mL}$ of water, with an addition of around $10 \mathrm{~mL}$ of concentrated hydrochloric acid. The solution was refluxed for about $48 \mathrm{~h}$, changing the solvent every $24 \mathrm{~h}$, in order to remove the non-encapsulated external salts from the samples. The sample was collected by filtration on top of a polycarbonate membrane $(0.2 \mu \mathrm{m}$ pore $)$, rinsed with water and dried in an oven at about $85^{\circ} \mathrm{C}$.

\subsection{Characterization techniques}

Thermogravimetric analysis was performed using a TA instrument TGA Q5000-IR in the facilities of MATGAS. The combustion of samples was done in air by using around $5 \mathrm{mg}$ of filled or empty carbon nanotubes in a high temperature $100 \mu \mathrm{L}$ platinum pan, using a gas flow of $25 \mathrm{~mL} / \mathrm{min}$ and a heating rate of $10^{\circ} \mathrm{C} / \mathrm{min}$.

Inductively coupled plasma (ICP) analysis consisted of two steps, namely the sample combustion and analysis. The combustion was achieved by microwave digestion (Milestone Ethos Plus) of about $5 \mathrm{mg}$ of nanotube sample in a mixture of concentrated nitric acid and hydrogen peroxide at $220{ }^{\circ} \mathrm{C}$. The acquired liquid was diluted with deionized water, and sample duplicates were analyzed. The analysis was performed on Agilent 7500ce Perkin Elmer Elan 6000 ICP-MS or on a Perkin Elmer Optima 3200RL ICP-OES. 
Elemental analysis (EA) of carbon nanotubes was performed at least on two replicas (around $1 \mathrm{mg}$ per analysis), using an elemental analyzer EA 1108 Instrument by adding vanadium(V) oxide and tin to ease the combustion, and using sulfanilamide as a pattern.

Brunauer-Emmett-Teller (BET) analysis was performed on about $2 \mathrm{mg}$ of empty MWCNTs. These nanotubes were annealed at different temperatures, 900, 1000, 1100, 1200 or $1300{ }^{\circ} \mathrm{C}$ under vacuum in a silica tube. After opening of the silica tubes, the nanotubes underwent a treatment of adsorbed gas removal at $300{ }^{\circ} \mathrm{C}$ for 15 hours. This was followed by nitrogen adsorption/desorption in cryo-environment, using liquid nitrogen as adsorbent.

Raman spectra were obtained using a Horiba Jobin Yvon instrument, operating at $532 \mathrm{~nm}$ wavelength and using a 50x objective. Raman spectra were recorded on thin films of the carbon nanotube samples. These were prepared by dropping isopropanol dispersions onto preheated glass substrates $\left(\sim 70^{\circ} \mathrm{C}\right)$.

X-ray photoelectron spectroscopy (XPS) measurements were recorded in a Kratos AXIS ultra DLD spectrometer using a monochromatic Al Ka. All samples were introduced in the preparation chamber simultaneously and on the same substrate $(\mathrm{Cu})$ to maintain the analysis conditions invariable. The $\mathrm{C} 1 \mathrm{~s}$ peak was set to $\mathrm{BE} 284.8 \mathrm{eV}$.

Electron microscopy was performed using a FEI Magellan 400L XHR SEM at $20 \mathrm{keV}$ in transmitted electrons mode using a high angle annular dark field (HAADF) STEM detector and a specially adapted holder was used for sample visualization. Energy dispersive X-Ray (EDX) spectra were acquired using a FEI Tecnai G2 F20 operated at $200 \mathrm{keV}$ and equipped with an EDAX super ultra-thin window (SUTW) X-ray detector. The samples were deposited onto a copper grid coated with a lacey carbon film (Agar Scientific) from a dispersed CNT solution in hexane or o-dichlorobenzene (Sigma Aldrich). 
Superconducting Quantum Interference Device (SQUID) analyses, using Quantum design MPMS XL-7T, were performed on carbon nanotubes using $10 \mathrm{~K}$ (in liquid nitrogen) under an external DC magnetic field. Hysteresis loops were taken in the range between -50000 to +50 000 Oe_ENREF_23 to monitor the catalyst content. CNTs were placed into a gelatin capsule (about $5 \mathrm{mg}$ ) and fixed with non-magnetic glass wool to avoid sample movement during the measurement.

\subsection{In vitro studies}

\subsubsection{Cell Culture}

Human epithelial bronchial immortalized cells (Beas-2B, ATCC, CRL-9609) were maintained and passaged in RPMI 1640 media containing glutamine (Sigma-Aldrich, UK) supplemented with $10 \%$ FBS (Thermo Scientific, UK), $50 \mu \mathrm{g} / \mathrm{mL}$ Penicillin, $50 \mu \mathrm{g} / \mathrm{mL}$ Streptomycin (SigmaAldrich, UK) at $37{ }^{\circ} \mathrm{C}$ in $5 \% \mathrm{CO}_{2}$. Cells were passaged twice a week using Trypsin-EDTA 0.05 $\%$ (Sigma-Aldrich, UK) when reached $80 \%$ confluence. Activity of trypsin was stopped using $10 \%$ FBS. Human epithelial breast cancer cells (MCF-7, ATCC, HTB-22) were maintained in EMEM media (Sigma-Aldrich, UK) supplemented with $10 \% \mathrm{FBS}, 50 \mu \mathrm{g} / \mathrm{mL}$ Penicillin, 50 $\mu \mathrm{g} / \mathrm{mL}$ Streptomycin at $37{ }^{\circ} \mathrm{C}$ in $5 \% \mathrm{CO}_{2}$. Cells were passaged twice a week using TrypsinEDTA $0.05 \%$ at $80 \%$ confluence. Activity of trypsin was stopped using $10 \%$ FBS.

\subsubsection{Cell Culture treatment}

Depending on the experiment, cells were seeded in 96 (LDH assay), 12 (FACS analysis) or 6 (ImageStream) well plates (Costar, Sigma) and treated when reached 70-80\% confluence. All the treatments were performed in the cell culture medium in the absence of FBS, $10 \%$ FBS was 
added to each well $4 \mathrm{~h}$ after the treatment. Empty, $\mathrm{NaI}$ and $\mathrm{GdCl}_{3}$ filled $\mathrm{MWCNTs}$ were dispersed in the corresponding cell culture media in order to obtain the concentration of 0.5 $\mathrm{mg} / \mathrm{mL}$. CNTs were sonicated for $5 \mathrm{~min}$ before making dilutions for the treatment, in order to assure the proper dispersibility of the material. Cells were exposed to $12.5-25-50-100 \mu \mathrm{g} / \mathrm{mL}$ MWCNTs, NaI@MWCNTs, GdCl $3 @$ MWCNTs for 24 h.

\subsubsection{Annexin V-Alexa Fluor®488 conjugate/PI Assay}

After $24 \mathrm{~h}$ of treatment at indicated concentrations, supernatants were collected and cells were gently washed 3 times with PBS $\mathrm{Ca}^{2+} / \mathrm{Mg}^{2+}$ (Sigma-Aldrich, UK). Annexin-V staining was performed according to the instructions of the manufacturer (Thermo Fisher Scientific, UK). In brief, cells were trypsinized for 5 minutes and merged with corresponding supernatants, centrifuged at $1500 \mathrm{rpm}$ for $5 \mathrm{~min}$, then re-suspended in $100 \mu \mathrm{L}$ Annexin binding buffer (Thermo Fisher Scientific, UK) and stained with $2 \mu \mathrm{L}$ Annexin V-Alexa Fluor®488 conjugate for 20 min at $15-25^{\circ} \mathrm{C}$. Propidium Iodide $(1 \mathrm{mg} / \mathrm{mL}$, Sigma) was added shortly before the analysis to the final concentration of $1.5 \mu \mathrm{g} / \mathrm{mL} .10000$ cells were analysed on a BD FACSVerseTM flow cytometer using $488 \mathrm{~nm}$ excitation and $515 \mathrm{~nm}$ and $615 \mathrm{~nm}$ band pass filters for Annexin $\mathrm{V}$ and PI detection, respectively. Electronic compensation of the instrument was performed to exclude overlapping of the two emission spectra. Material alone was run in order to set up the gates including the cell population for the analysis. Percentage of unstained, cells stained with Annexin V, PI or both was calculated.

\subsubsection{Modified LDH Assay}

LDH assay was modified to avoid any interference coming from the interactions of the material with assay[48]. Briefly, LDH content was assessed in intact cells that survived the 
treatment, instead of detecting the amount of LDH released in the media upon treatment. Media was aspirated and cells were lysed with $100 \mu \mathrm{L}$ of lysis buffer for $45 \mathrm{~min}$ at $37{ }^{\circ} \mathrm{C}$ to obtain cell lysates, which was then centrifuged at 4,000 rpm for $20 \mathrm{~min}$ in order to pellet down the material. $50 \mu \mathrm{L}$ of the supernatant of the cell lysate was mixed with $50 \mu \mathrm{L}$ of LDH substrate mix (Promega, UK) in a new 96-well plate and incubated for $15 \mathrm{~min}$ at room temperature, after which $50 \mu \mathrm{L}$ stop solution was added.

$$
\text { Cell Survival } \%=\left(\alpha_{490 \mathrm{~nm}} \text { of treated cells } / \alpha_{490 \mathrm{~nm}} \text { of untreated cells }\right) \times 100
$$

The absorbance was read at $490 \mathrm{~nm}$ using a plate reader. The amount of LDH detected represented the number of cells that survived the treatment. The percentage cell survival was calculated using the equation above.

\subsubsection{Imagestream analysis}

At the end of the exposure to MWCNTs, media was removed, cells were thoroughly washed with PBS containing $\mathrm{Ca}^{2+} / \mathrm{Mg}^{2+}$ and cells were harvested. Cell suspension was centrifuged for 5 min at $1500 \mathrm{rpm}$ at $4^{\circ} \mathrm{C}$ and the pellet was resuspended in $500 \mu \mathrm{l}$ of $4 \%$ para-formaldehyde (PFA, Thermo Fischer, UK). After 20 min of incubation in PFA, cells were rinsed three times with PBS and finally resuspended in $50 \mu \mathrm{l}$ of PBS. At least 2,500 cells were analyzed using AmnisImageStream ${ }^{\mathrm{x}}$ platform (AmnisImageStream MKII, Millipore UK) and Inspire ${ }^{\mathrm{TM}}$ system software (Amnis). Camera magnification was 60x, $785 \mathrm{~nm}$ excitation laser was set at $0.02 \mathrm{~mW}$. Images were acquired with a normal depth of field, providing a cross-sectional image of the cell with a $2.5 \mu \mathrm{m}$ depth of focus. A mask representing the whole cell was defined by the bright-field image. An internal mask was defined by eroding the whole cell mask for 6 pixels (equivalent to 3 $\mu \mathrm{m}$, as the size of 1 pixel is $0.5 \mu \mathrm{m}$ ) in order to eliminate the signal coming from the NPs attached to the cell surface. The results were analyzed by IDEAS software (Amnis). Values of 
the internalization score and mean side scatter intensity were calculated for at least 500 cells per sample.

\section{Results and Discussion}

As-received MWCNTs were initially treated with a combined $2 \mathrm{~h}$ steam and $\mathrm{HCl}$ treatment in order to open their ends, and remove carbonaceous and catalytic impurities.[49] The amount of catalyst present is important from the point of view of future applications of the material, since it can dominate the behavior of the sample, such as the electrochemical response, $[50,51]$ and it can also induce oxidative stress or toxicity to cells when employed in the biomedical field.[52-54] The metal content present in purified MWCNTs turned out to be 0.002 wt. $\%$ as determined by SQUID. SQUID was employed because magnetic susceptibility measurements have been advocated as an ultrasensitive technique for quality control of CNT samples since it allows the detection of traces of magnetic metal impurities embedded in purified carbon nanotubes.[55]

In order to investigate the role of temperature on the degree of closed-ended MWCNTs, purified nanotubes were annealed at different temperatures, namely $900{ }^{\circ} \mathrm{C}, 1000{ }^{\circ} \mathrm{C}, 1100{ }^{\circ} \mathrm{C}$, $1200{ }^{\circ} \mathrm{C}$ and $1300{ }^{\circ} \mathrm{C}$. It is known that single-walled carbon nanotubes spontaneously close upon cooling after being annealed above $700-900{ }^{\circ} \mathrm{C} .[37,56]$ Therefore, the annealing treatment could also provide the necessary energy needed to close the ends of multi-walled carbon nanotubes to a certain extent. To assess whether annealing MWCNTs at these temperatures had any effect on closing their ends, we determined the surface area of the samples. The surface area of different materials can be measured by using the Brunauer-Emmett-Taller (BET) model developed back in 1938, based on nitrogen gas adsorption and desorption at the boiling point of the adsorbate, i.e.

77 K (Equation S1).[57] Open-ended carbon nanotubes should have a higher surface area 
compared to their closed-ended analogues due to gas adsorption in the inner cavity of the carbon nanotubes. Bundling, aggregation, functional groups and defects present in carbon nanotube samples can also have an impact on the surface area of the material.[58] Therefore, steam purification was employed on the as-received CNTs to avoid the introduction of functional groups onto the CNT walls,[59] and all the thermally annealed samples were processed in the same manner. In this way, we should be able to correlate the obtained BET surface area with the amount of opened/closed MWCNT ends since bundling and aggregation of carbon nanotubes is expected to be preserved after annealing at the employed temperatures. Figure 1a shows the BET surface area of raw, purified and thermally annealed samples. We observed a type IV adsorption isotherm which classifies the samples as mesoporous materials (Figure S1). Pristine raw material comes with mostly closed ends, while steam purification has been proven as an efficient method in opening the CNT extremities.[49] This has also been observed by BET where a $50 \%$ increase in the surface area was observed after purifying the CNTs (from $283.2 \mathrm{~m}^{2} \mathrm{~g}^{-1}$ for raw to 429.6 $\mathrm{m}^{2} \mathrm{~g}^{-1}$ for purified), indicating the successful removal of the CNT tips with the employed protocol. As mentioned, the purification treatment also removes unwanted impurities which will also contribute to the measured surface area. 

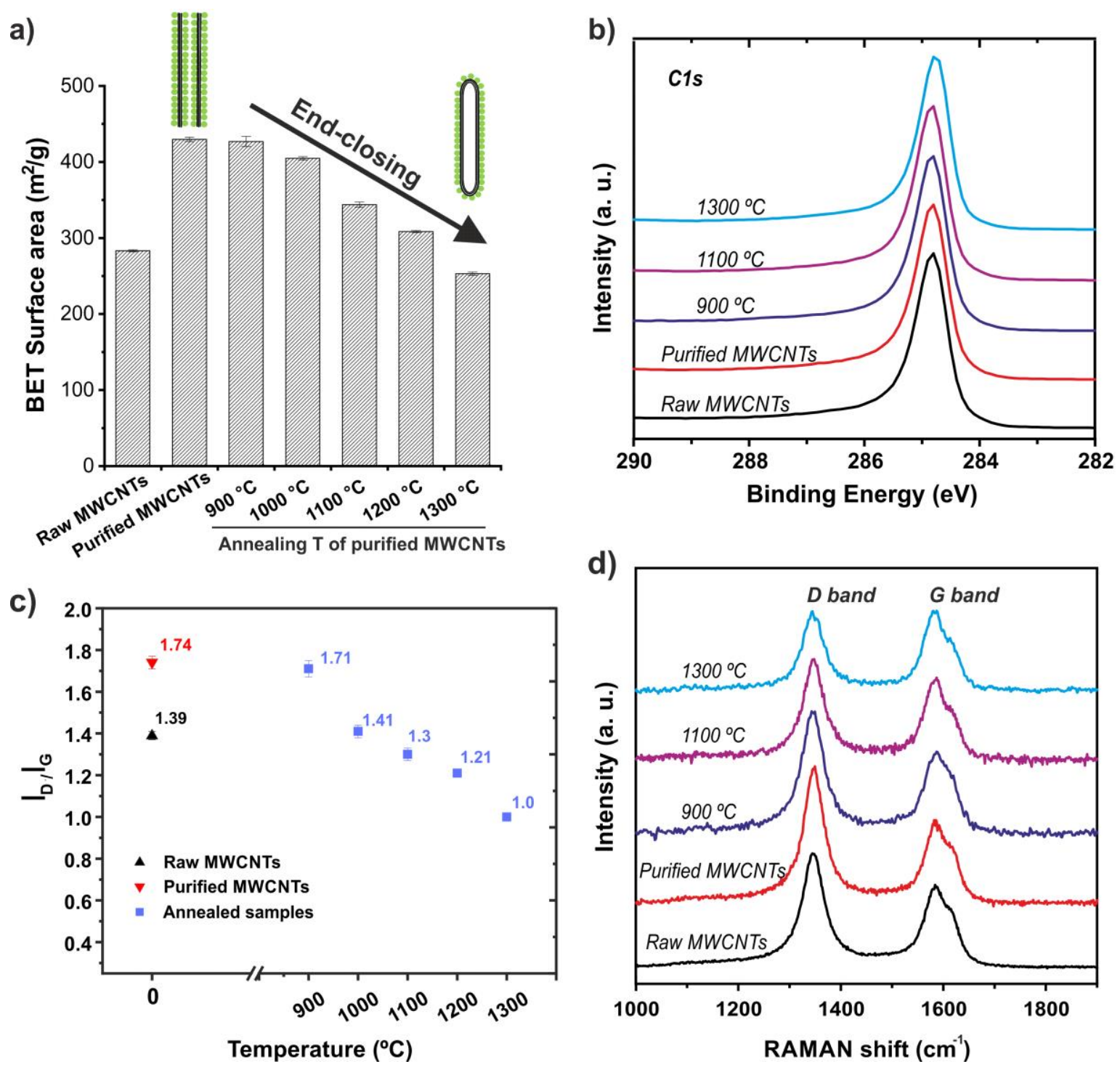

Figure 1. a) BET surface area (Schematic representation: black lines - MWCNTs; green dots $\mathrm{N}_{2}$ molecules), b) normalized XPS spectra over the C1s region, with the C1s peak set to a BE of $284.8 \mathrm{eV}, \mathrm{c}) \mathrm{I}_{\mathrm{D}} / \mathrm{I}_{\mathrm{G}}$ Raman ratios and d) normalized Raman spectra of raw, purified MWCNTs (2 h steam and $\mathrm{HCl}$ ), and purified MWCNTs after being annealed at different temperatures (between $900-1300{ }^{\circ} \mathrm{C}$ ). 
A continuous decrease in the BET surface area is observed upon increasing the thermal annealing temperature of the purified sample (open-ended). This decrease in the surface area is attributed to the spontaneous closure of the nanotube ends upon cooling. Therefore, the higher the temperature of annealing the higher the degree of closed ends. The formation of closed-ended single-walled carbon nanotubes has been previously reported when employing temperatures in the range of $700{ }^{\circ} \mathrm{C}-900{ }^{\circ} \mathrm{C}(1-2 \mathrm{~nm}$ in diameter $) .[37,56]$ The BET surface area recorded at 900 ${ }^{\circ} \mathrm{C}$ for their multi-walled counterparts is similar, within experimental error, to the surface area of purified MWCNTs (open-ended). This indicates that annealing MWCNTs at $900{ }^{\circ} \mathrm{C}$ has a nondetectable effect on closing their ends. Therefore, since the inner diameter of MWCNTs is larger than the diameter of SWCNTs, it is necessary to anneal at higher temperatures to induce the spontaneous end-closing; i.e. $1000{ }^{\circ} \mathrm{C}-1300{ }^{\circ} \mathrm{C}$ in the present study.

The mechanism for end-closing would need further investigation. Steam has been reported to avoid the introduction of functional groups onto the CNT structure, at least to a detectable level with previously performed analyses.[49, 59, 60] However, it is likely that the end carbons of the CNT framework are attached to other atoms rather than staying bare. First-principles calculations on the energetics of opening and closing SWCNTs have shown that an oxygen (hydrogen) rim can stabilize the edge of open nanotubes.[61] In the same study, Artacho et al. showed that the removal of oxygen atoms that saturate the carbon dangling bonds at the tips, which will take place upon thermal annealing of the samples, would result in the formation of an unsaturated open tube which would be energetically unfavourable. As a consequence, end-closing would be expected, since a cap configuration would be more stable than an unsaturated open ended geometry. Taking into account the small amount of Fe present in the samples, the end closing 
process is not expected to be catalyzed by the residual metal species employed for the growth of the CNTs.

As mentioned earlier, steam has been reported to preserve the integrity of the tubular wall structure. Nevertheless, this aspect was further investigated since the presence of functional groups could induce an increase in the surface area of the samples. XPS and Raman measurements were next carried out and selected spectra are shown in Figure 1 (Figure S2 includes data for all the samples). The XPS C1s region is sensitive to different functional groups.[62] The peak at $284.8 \mathrm{eV}$ is attributed to the conjugated carbon network of the graphitic structure. Graphitic derivatives containing O-based aliphatic groups would appear as shoulders at higher binding energies related to $\mathrm{sp}^{3}$ bonding. In the present case, no significant differences can be observed between the XPS spectra of raw, purified and thermally annealed samples. This confirms that changes in the BET surface area can be attributed to the degree of open/closed ends, since the presence functional groups on the sidewalls can be discarded. As mentioned earlier, carbon atoms at the tips of MWCNTs might be terminated with functional groups. However, due to the aspect ratio of MWCNTs even if heteroatoms were present at the tips their detection would be difficult. Elemental analysis of hydrogen on steam purified MWCNTs revealed a $\mathrm{H}$ content below 0.2 at.\%. [59] Yet, we quantified by XPS the amount of oxygen and carbon present in the different samples to check whether there was any trend in the oxygen content after annealing the purified MWCNTs at different temperatures. To get statistical information, the atomic content was determined by measuring the areas of the $\mathrm{C} 1 \mathrm{~s}$ and $\mathrm{O} 1 \mathrm{~s}$ signals from three different scans. As it can be seen in Table S1 a low amount of oxygen is detected in all the samples. Despite quantitative comparison between two independent samples might lie within experimental error, a general trend can be noted where lower amounts of oxygen 
are detected for samples annealed at higher temperatures (from $1.84 \pm 0.13$ at. $\%$ for purified MWCNTs down to $0.65 \pm 0.09$ at.\% after annealing the purified MWNCTs at $\left.1300{ }^{\circ} \mathrm{C}\right)$. The continuous decrease in the oxygen content upon increasing the annealing temperature could be attributed to the removal of oxygen functionalities from the tips leading to end-closing. Due to the aspect ratio of MWCNTs the detection of these oxygen functionalities introduced by the steam opening step is challenging by analysis of the C1s peak or FTIR.

Raman spectroscopy reflects structural changes on the samples. G-band and D-band, typically observed in graphite-like structures, are located at ca. $1350 \mathrm{~cm}^{-1}$ and ca. $1590 \mathrm{~cm}^{-1}$ respectively. The first one arises from $\mathrm{sp}^{2}$-type bonds vibrations of a highly ordered conjugated system. On the other hand, D-band appears after inducing the formation of structural defects distorting the aromaticity of the planar network. [63] Since having opened tips induces disruptions of the conjugated system, the intensity ratio between the $D$ and $G$ bands $\left(\mathrm{I}_{\mathrm{D}} / \mathrm{I}_{\mathrm{G}}\right)$ could provide useful information to estimate how successful is the protocol to close the nanotubes. $\mathrm{I}_{\mathrm{D}} / \mathrm{I}_{\mathrm{G}}$ ratios of the samples annealed between $900{ }^{\circ} \mathrm{C}$ and $1300{ }^{\circ} \mathrm{C}$ are presented in Figure 1c. Data of both raw and purified MWCNTs are included for comparison. Registered values correspond to the average of three scans of different areas of the sample (Table S2). An increase of the $\mathrm{I}_{\mathrm{D}} / \mathrm{I}_{\mathrm{G}}$ ratio is observed after steam purification, from $1.39 \pm 0.02$ to $1.74 \pm 0.03$, which has been previously assigned to the end opening. By thermal annealing the purified MWCNTs, a continuous decrease in the $\mathrm{I}_{\mathrm{D}} / \mathrm{I}_{\mathrm{G}}$ ratio is observed upon increasing the annealing temperature, which can be attributed to endclosing of the MWCNT tips. The lowest $\mathrm{I}_{\mathrm{D}} / \mathrm{I}_{\mathrm{G}}$ is recorded for the sample treated at $1300{ }^{\circ} \mathrm{C}(1.0 \pm$ 0.02), indicating the highest degree of end closing. It is worth noting that the sample treated at $900^{\circ} \mathrm{C}$ presents the same $\mathrm{I}_{\mathrm{D}} / \mathrm{I}_{\mathrm{G}}$ ratio, within experimental error, to the purified MWCNTs suggesting that no significant structural changes are produced by annealing steam purified 
MWCNTs at $900^{\circ} \mathrm{C}$. This is in agreement with BET analysis, which revealed that higher temperatures $\left(1000{ }^{\circ} \mathrm{C}-1300{ }^{\circ} \mathrm{C}\right.$ in the present study) were needed to close the ends of the MWCNTs.

To provide direct evidence that both the decrease in the surface area and the Raman measurements can be correlated with the end-closing of MWCNTs, we next investigated the potential of annealing samples of multi-walled carbon nanotubes in this range of temperatures to permanently seal materials in their interior. Purified open-ended MWCNTs were filled with a variety of metal halides by melt filling, namely $\mathrm{NaI}, \mathrm{KI}, \mathrm{BaI}_{2}, \mathrm{GdCl}_{3}$ and $\mathrm{SmCl}_{3}$. Initially, both MWCNTs and the selected metal halide were ground together and placed inside a silica tube that was sealed under vacuum. The mixture was annealed in the range between $1000{ }^{\circ} \mathrm{C}$ and $1300{ }^{\circ} \mathrm{C}$ since these temperatures should lead to different degrees of closed-ended MWCNTs. All the investigated metal halides are molten at these temperatures, thus allowing both filling and endclosing of MWCNTs in a single step. After filling the different materials inside multi-walled carbon nanotubes, the resulting samples were properly washed to remove the external, nonencapsulated compounds. Having closed ends should allow the selective removal of the external material while preserving the encapsulated metal halides.

Initially we confirmed that at $1000{ }^{\circ} \mathrm{C}-1100{ }^{\circ} \mathrm{C}$, the lowest temperature range where a significant decrease in the surface area is observed, it was already possible to seal $\mathrm{KI}$ and $\mathrm{NaI}$ in the cavities of MWCNTs. The prepared multi-walled nanocapsules were analysed by high angle annular dark-field (HAADF) using a scanning electron microscope in transmission mode (T/SEM). In this imaging modality, the intensity offered by an element present in the sample is proportional to its atomic number. Therefore, carbon appears with a pale grey contrast and the encapsulated material as bright lines following the shape of the carbon nanotubes, as it can be 
seen in Figure 2a and $2 b$. The absence of non-external metal iodides can also be easily confirmed in this imaging modality. As a control, we checked whether with open ends present, the material would leak out from the nanotubes during the washing step, leaving them empty. A sample of steam purified open-ended MWCNTs was filled with NaI at $700{ }^{\circ} \mathrm{C}$. According to the analysis performed so far, at this temperature the ends of the MWCNTs should remain opened. T/SEM images of the sample after the filling experiment, prior to the washing step, reveals the presence of NaI in the interior of MWCNTs. After extensively washing the open-ended NaI filled MWCNTs, empty cavities are observed (Figure S3). This confirms the necessity of having closed ends at the tips of filled carbon nanotubes to preserve the encapsulated compounds during the washing step. 

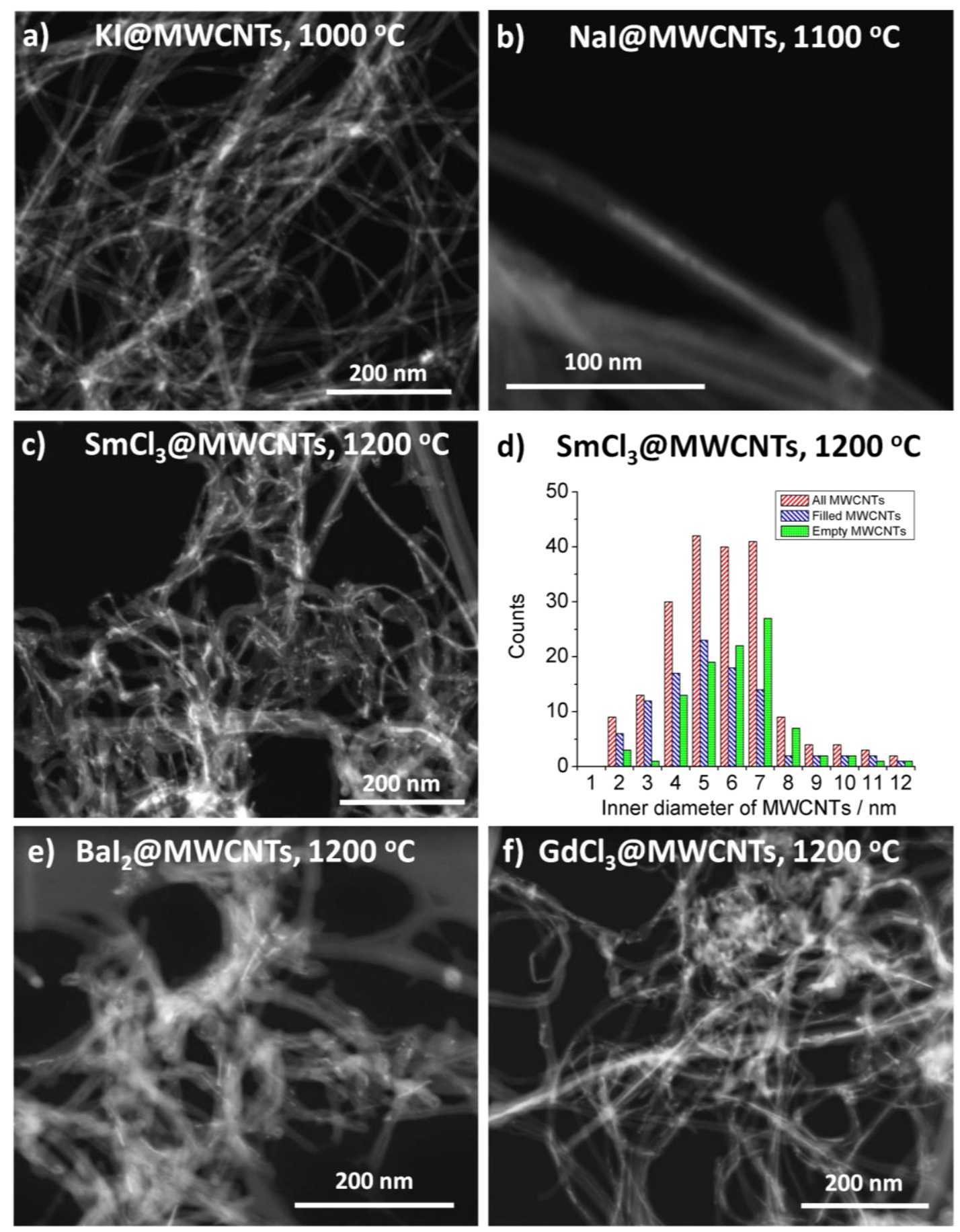

Figure 2. Multi-walled carbon nanocapsules of a) KI@MWCNTs prepared at $1000{ }^{\circ} \mathrm{C}$, b) NaI@MWCNTs at $1100{ }^{\circ} \mathrm{C}$, c) SmCl $\mathrm{Sm}_{3} @$ MWCNTs at $1200{ }^{\circ} \mathrm{C}$, d) histogram showing the inner diameter distribution and the amount of empty, filled and both filled and empty (all) MWCNTs in a sample of $\mathrm{SmCl}_{3} @ \mathrm{MWCNT}$ prepared at $1200{ }^{\circ} \mathrm{C}$, e) $\mathrm{BaI}_{2} @ \mathrm{MWCNTs}$ at $1200{ }^{\circ} \mathrm{C}$ and f) 
$\mathrm{GdCl}_{3} @ \mathrm{MWCNTs}$ at $1200{ }^{\circ} \mathrm{C}$. Images have been acquired by HAADF T/SEM and show the presence of filled material after washing the samples.

Next, we investigated the role of temperature by filling samarium(III) chloride into MWCNTs $\left(\mathrm{SmCl}_{3} @ \mathrm{MWCNTs}\right)$ at 1100,1200 and $1300{ }^{\circ} \mathrm{C}$ for $12 \mathrm{~h}$. After a subsequent proper washing of the non-encapsulated material, all samples show the presence of filling inside their cavities by HAADF T/SEM analysis (Figure 2c and Figure S4). Interestingly, TGA under flowing air reveals that the material annealed at $1100{ }^{\circ} \mathrm{C}$ has a lower filling yield compared to the sample annealed at $1200{ }^{\circ} \mathrm{C}(11.3 \mathrm{wt} . \%$ vs $23.5 \mathrm{wt} . \%)$. This is in agreement with BET data that already infers a higher degree of closed ends at $1200{ }^{\circ} \mathrm{C}$ than at $1100{ }^{\circ} \mathrm{C}$. Even if the encapsulation efficiency was the same at both temperatures, more material would be removed from the inner cavities of open-ended nanotubes by washing the sample annealed at $1100{ }^{\circ} \mathrm{C}$, since more nanotubes remain opened after annealing at this temperature than at $1200{ }^{\circ} \mathrm{C}$. The filling yield was determined by TGA using a previously reported equation developed for filled single-walled carbon nanotubes.[64] Important to notice is the presence of silica particles, or even chunks in the sample annealed at $1300{ }^{\circ} \mathrm{C}$ (Figure S4c), probably due to the recrystallization of the silica ampoule, employed for the synthesis, upon cooling that might result in the introduction of silica impurities, from the inner wall of the ampoule, into the sample. Actually, the silica ampoule loses its transparency and becomes white after annealing at $1300^{\circ} \mathrm{C}$. Therefore, special care was taken to remove silica particles from the sample prior to the quantification of the oxygen content by XPS. From the filling experiments performed so far it becomes clear that the range of 1000 ${ }^{\circ} \mathrm{C}-1200{ }^{\circ} \mathrm{C}$ is the most interesting to achieve samples of closed-ended filled MWCNTs. 
As mentioned earlier, whereas the ends of SWCNTs with diameters of 1-2 nm can be closed upon annealing in the range of $700{ }^{\circ} \mathrm{C}-900{ }^{\circ} \mathrm{C},[37,56]$ ENREF 34 higher temperatures are needed when using MWCNTs. The process of end-closing is clearly diameter dependent, so we next determined the diameter distribution of the employed MWCNTs, and whether the observed MWCNTs where filled or empty. The statistical analysis was performed on a sample of $\mathrm{SmCl}_{3} @ \mathrm{MWCNTs}$ prepared at $1200^{\circ} \mathrm{C}$. From about 200 nanotubes that were analyzed by TEM, $50 \%$ of them turned out to be filled, while the other $50 \%$ remained empty. The diameter distribution determined by TEM shows that the sample contains CNTs with inner diameters in the range of 2-12 nm, being the major fraction of both filled and empty nanotubes between 4 and $7 \mathrm{~nm}$ (Figure 2d). It is worth noting that the amount of filled MWCNTs is slightly higher for small diameters $(2-5 \mathrm{~nm})$. With the increase of the inner cavity of MWCNTs (6 $\mathrm{nm}$ and above), this trend is inversed and the fraction of empty nanotubes becomes slightly higher than the filled ones. This suggests that at this annealing temperature bigger nanotubes are not closed and the filled material gets removed during the washing step. Therefore, more energy would be needed to increase the amount of closed MWCNTs with large diameters.

To further explore the versatility of the one step filling-closing protocol, additional materials $\left(\mathrm{BaI}_{2}\right.$ and $\left.\mathrm{GdCl}_{3}\right)$, were filled at $1200{ }^{\circ} \mathrm{C}$, since a high degree of filling should be achieved while avoiding contamination from the silica ampoule. HAADF T/SEM reveals the presence of filled material inside the cavities of carbon nanotubes and absence of external metal halides (Figure 2e and 2f). A summary of the different multi-walled carbon nanocapsules that have been prepared at different annealing temperatures is presented in Table 1. 
Table 1. Summary of metal halide multi-walled carbon nanocapsules (closed-ended filled MWCNTs) free of non-encapsulated external material, prepared under different conditions. As a control, an additional sample of $\mathrm{NaI}$ annealed at $700{ }^{\circ} \mathrm{C}$ was prepared but is not included in the table because the ends of the MWCNTs remained opened after the treatment.

\begin{tabular}{lcccc}
\hline Filled material & \multicolumn{4}{c}{ Temperature of annealing $/{ }^{\circ} \mathbf{C}$} \\
\cline { 2 - 5 } & $\mathbf{1 0 0 0}^{\circ} \mathbf{C}$ & $\mathbf{1 1 0 0}^{\circ} \mathbf{C}$ & $\mathbf{1 2 0 0}^{\circ} \mathbf{C}$ & $\mathbf{1 3 0 0}^{\circ} \mathbf{C}$ \\
\hline KI & $\mathrm{X}$ & & & \\
\hline $\mathbf{N a I}$ & $\mathrm{X}$ & $\mathrm{X}$ & & \\
\hline $\mathrm{SmCl}_{3}$ & & $\mathrm{X}$ & $\mathrm{X}$ & $\mathrm{X}$ \\
\hline $\mathrm{BaI}_{2}$ & & & $\mathrm{X}$ & \\
\hline $\mathrm{GdCl}_{3}$ & & & $\mathrm{X}$ & \\
\hline
\end{tabular}

As mentioned, after the annealing step each of the samples was washed to remove the material external to the carbon nanotube walls. We noticed that the removal of external material was easier when employing MWCNTs than SWCNTs filled with the same metal halides,[65] and fewer washing steps were necessary to remove the non-encapsulated compounds in the present study. The complete removal of the excess of material after filling SWCNTs might even require the use of a combined dialysis and Soxhlet system.[66] This implies that the synthesis process to achieve clean nanocapsules is faster when using MWCNTs than SWCNTs.

Different degrees of filling can be observed in the images presented in Figure 2, which will depend on the material and temperature employed for the synthesis.[67] The filling yield was quantitatively determined by thermogravimetric analysis (TGA).[64] Alternatively, the filling yield could also be quantified by inductively coupled plasma (ICP) analysis, and indirectly from elemental analysis (EA) of carbon assuming that the non-carbon portion arises from the filled material and iron catalyst content known to be present in the purified samples. Good filling 
yields were obtained for the prepared multi-walled carbon nanocapsules, in the range of 7.5 to 28.8 wt. \% (Table S3).

$\mathrm{GdCl}_{3}$ and $\mathrm{SmCl}_{3}$ filled multi-walled carbon nanotubes annealed at $1200{ }^{\circ} \mathrm{C}$ were analyzed by high-resolution transmission electron microscopy and HAADF-STEM to determine whether the tips of the CNTs were opened or closed. Figure 3 shows an individual nanotube with both ends being closed (areas A and C) and the presence of material confined inside the cavity. This is a direct proof of the closure of both ends after annealing, which will prevent the release of the encapsulated compound during the washing protocol. Additional electron microscopy images of individual MWCNTs, filled and with both ends closed, are included in Figures S5-S7.

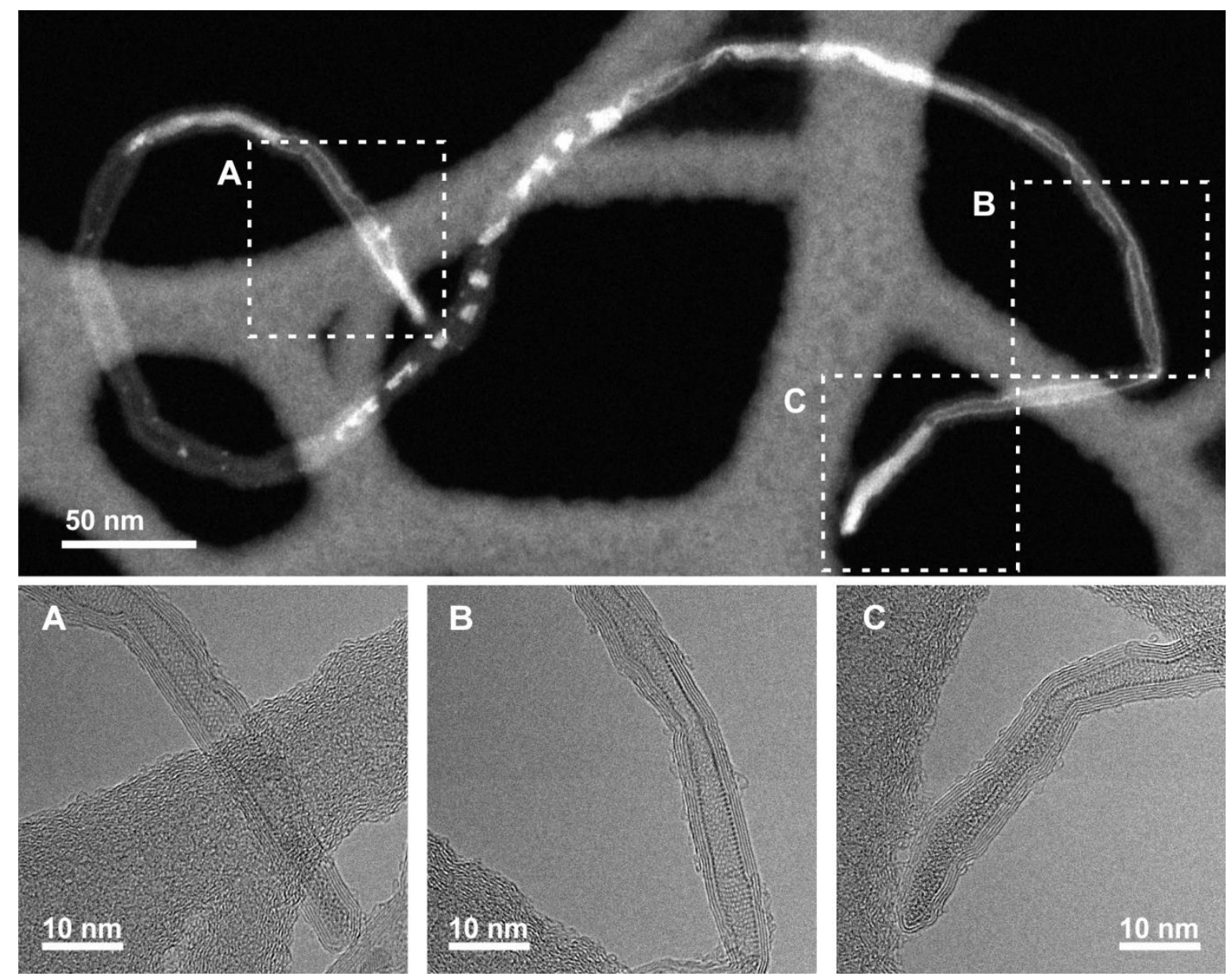


Figure 3. HAADF STEM image of a $\mathrm{GdCl}_{3}$ filled multi-walled carbon nanotube $\left(\mathrm{GdCl}_{3} @ \mathrm{MWCNT}\right)$ showing the presence of filling material and both ends being closed. HRTEM images of regions $\mathrm{A}$ and $\mathrm{B}$, confirming the presence of closed tips and region $\mathrm{B}$ revealing the formation of a single-layered $\mathrm{GdCl}_{3}$ nanotube.

Bulk $\mathrm{GdCl}_{3}$ exhibits polymorphism and can crystallize in both the hexagonal $\mathrm{UCl}_{3}$ type structure or in the orthorhombic $\mathrm{PuBr}_{3}$ type structure,[42] the latter being a van der Waals solid formed upon stacking sandwich layers of $\mathrm{GdCl}_{3}$ (Figure S8). As a consequence, the formation of $\mathrm{GdCl}_{3}$ nanocapsules resulted in the formation of single-layered inorganic nanotubes inside the cavities of MWCNTs. The contrast offered by $\mathrm{GdCl}_{3} @$ MWCNTs both in HRTEM and HAADF STEM is characteristic from the presence of metal halide inorganic nanotubes grown within carbon nanotubes (region $\mathrm{B}$ in Figure 3). $[5,7,19]$ In contrast, no filling of $\mathrm{GdCl}_{3}$ is observed when using $\mathrm{WS}_{2}$ nanotubes as templates.[68] Encapsulation of $\mathrm{GdI}_{3}$ into $\mathrm{WS}_{2}$ mainly resulted in the formation of continuous rod-like structures, although nanotube-like morphology was observed in some cases.[68] The possibility to encapsulate metal halides into both CVD grown CNTs and $\mathrm{WS}_{2}$ nanotubes indicates that filling would also be expected to occur into CNTs from other sources. The filling process is expected to take place through open-ends rather than through structural defects on the walls of the nanotubes.

A similar contrast was observed in the samples of $\mathrm{SmCl}_{3}$ by HAADF T/SEM and HRTEM, which is typical from the encapsulation of van der Waals solids, such as $\mathrm{GdCl}_{3}$ in the present study. Figure $4 \mathrm{a}$ presents a nanotube-nanowire junction of $\mathrm{SmCl}_{3}$. The crystallinity of both structures can be appreciated in the HRTEM image and also by FFT (Figure 4b). The formation of single-layered inorganic nanotubes of samarium chloride is of interest since bulk $\mathrm{SmCl}_{3}$ is not known to crystallize in a layered structure (according to ICSD, Inorganic Crystal Structure 
Database). We next performed a detailed analysis of this system to determine the presence of either nanowires or nanotubes in the interior of the multi-walled carbon nanocapsules. When a $\mathrm{SmCl}_{3}$ nanowire and a $\mathrm{SmCl}_{3}$ nanotube co-exist in the same individual MWCNT, such as in Figure $4 \mathrm{a}$, it would be counted as both nanowire and nanotube in the present analysis. As it can be seen in the histograms presented in Figure 4c, although the formation of $\mathrm{SmCl}_{3}$ nanowires is clearly preferred regardless of the inner diameter $(2-12 \mathrm{~nm})$, with $83 \%$ of filled tubes presenting $\mathrm{SmCl}_{3}$ nanowires, a substantial amount of $\mathrm{SmCl}_{3}$ nanotubes could be observed in the range of 3$8 \mathrm{~nm}$. This range of diameters is in excellent agreement with those reported for single-layered $\mathrm{PbI}_{2}$ nanotubes when using MWCNTs as templates.[5] 


\section{a)}

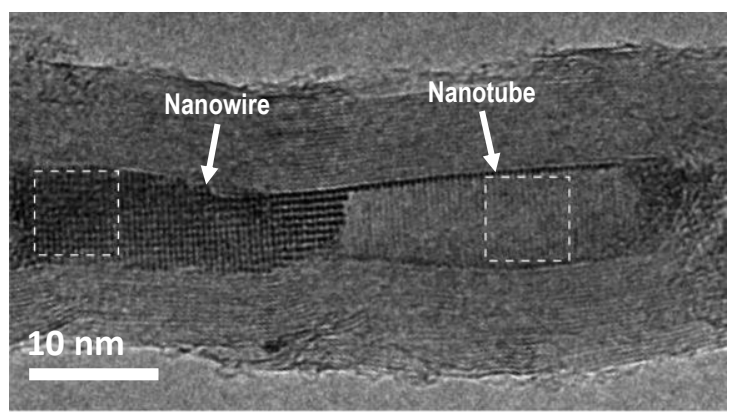

b)
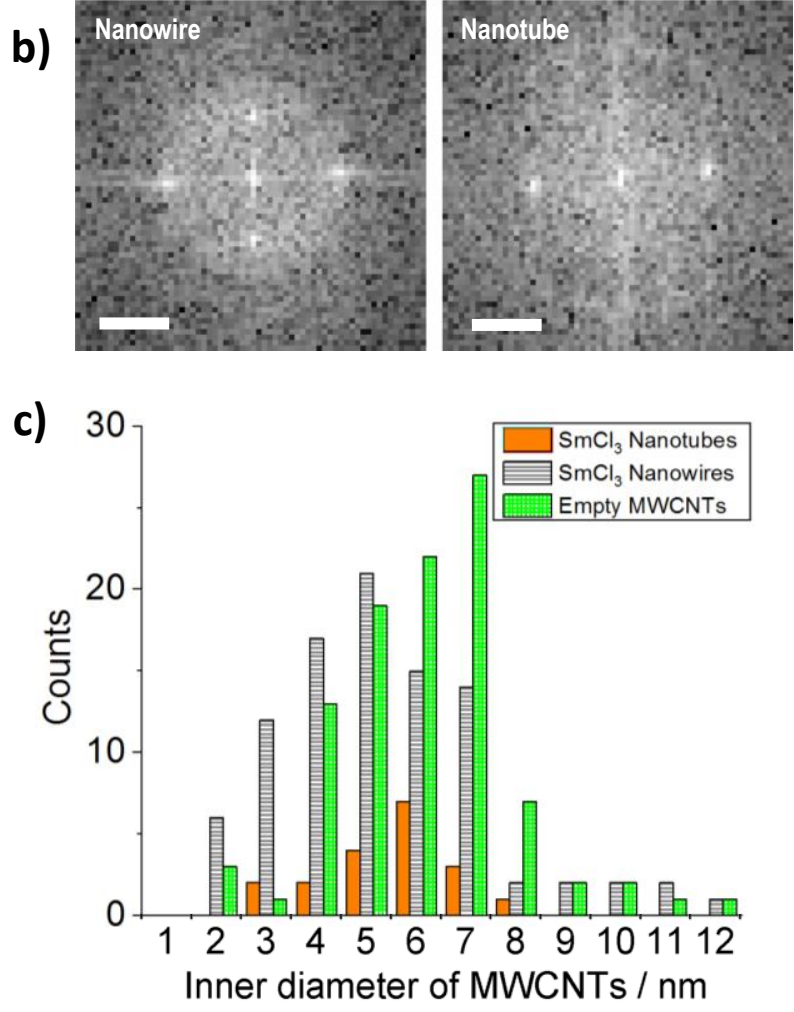

Figure 4. a) HRTEM image of $\mathrm{SmCl}_{3} @ \mathrm{MWCNTs}$ filled at $1200{ }^{\circ} \mathrm{C}$ revealing the presence of both $\mathrm{SmCl}_{3}$ nanotubes and nanowires inside the cavities of the MWCNTs. b) FFT of the areas marked with squares in a) showing the crystalline nature of both nanowires and nanotubes (scale bar $=2 \mathrm{~nm}^{-1}$ ). c) HRTEM images statistical analysis of the amount of $\mathrm{SmCl}_{3}$ inorganic nanotubes and nanowires present in the sample. 
As discussed earlier, nanocapsules are of interest for a wide variety of applications, including those in the biomedical field. Therefore, to complete the study we assessed internalization and cytotoxicity of two types of nanocapsules in vitro, namely NaI@MWCNTs (synthesized at 1000 ${ }^{\circ} \mathrm{C}$; Figure S9) and $\mathrm{GdCl}_{3} @ \mathrm{MWCNTs}$ (prepared at $1200{ }^{\circ} \mathrm{C}$ ), along with empty MWCNTs. We used nanocapsules prepared at different temperatures and filled with different metal halides, to assess whether either the processing conditions or the used compounds had any effect on the biocompatibility of the nanocapsules. Different levels of cytotoxicity have for instance been reported for halogenated graphene samples, using $\mathrm{Cl}, \mathrm{Br}$ and I.[69]

For successful diagnostic and therapeutic applications of CNTs filled with various compounds it is advantageous if they are efficiently taken up by the cells. CNTs are shown to be taken up by various cell types irrespectively of their chemical functionalization.[70] Internalization of CNTs takes place by active as well as passive translocation due to the "nano-needle" structure of the material.[71] In order to assess the uptake of empty or filled MWCNTs, we performed imaging flow cytometry analysis of the cells treated with MWCNTs for $24 \mathrm{~h}$ using escalating concentrations of the material. Imaging flow cytometry is a recently developed high-throughput technique enabling both to visualize the cells in the flow and to analyze them in a statistically relevant way based on a pixel-by-pixel analysis and comparison. Visualization of the cells in the flow is achieved using a high-resolution microscope and can be based on images acquired in bright-field, dark-field or using fluorescent channels. Due to the intrinsic ability of CNTs to absorb light they appear as black spots on the bright-field image and are easily distinguished from the rest of the cell (Figure 5a). Furthermore, this method enables to determine localization of the CNTs by applying an eroded mask on the bright-field image of the whole cell. In this way CNTs attached to the cellular surface are distinguished from the ones that are found inside the 
cell providing an accurate assessment of the uptake. Evaluation of the internalization of nanomaterial by cells using imaging flow cytometry has already been described for various nanomaterials as well as for the carbon nanotubes[72-75]. In order to eliminate the material that is attached on the surface of the cells a mask was applied on the bright-field image of the whole cell and the value of mean pixel intensity inside the eroded mask was calculated. Using this approach, we show that empty as well as MWCNTs filled with $\mathrm{NaI}$ or $\mathrm{GdCl}_{3}$ are efficiently taken up by MCF-7 cells in a dose dependent manner (Figure 5b). The mean pixel intensity inside the eroded mask is significantly different from the same value in untreated cells already after treatment with the lowest used dose $-12.5 \mu \mathrm{g} / \mathrm{mL}$ (Figure $5 \mathrm{~b}$ ). Values of the mean pixel intensity were found to increase with increasing concentrations of the material used for the treatment, indicating that the uptake of nanocapsules was a dose dependent process (Figure 5b).

a)

MCF-7

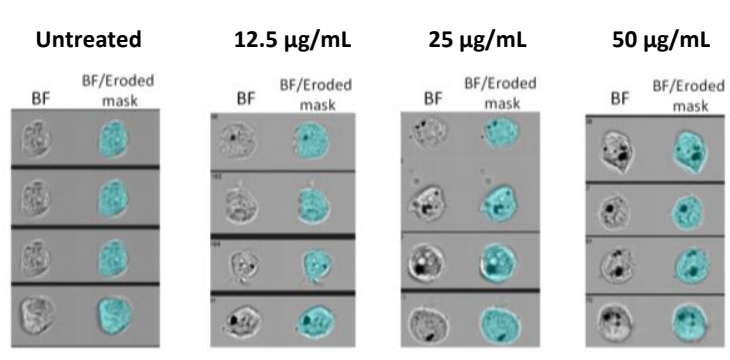

b)

MCF-7

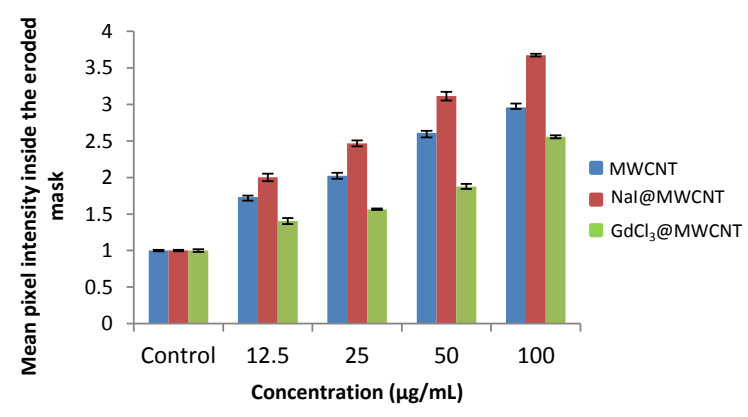


Figure 5. Uptake of empty or filled MWCNTs. a) Representative images captured by Amnis ImageStream $^{\mathrm{X}}$ of MCF-7 cells treated with $\mathrm{GdCl}_{3} @ M W C N T s$ for $24 \mathrm{~h}$ at 12.5, 25, $50 \mu \mathrm{g} / \mathrm{mL}$. First column shows the cells in bright-field (BF), second column shows images of the brightfield merged with the eroded mask. b) Normalized values of the mean pixel intensity inside the eroded mask. Results are expressed as mean value $\pm \mathrm{SD}(\mathrm{n}=3)$.

Subsequently, we aimed to evaluate the cytotoxicity of empty or MWCNTs filled with NaI or $\mathrm{GdCl}_{3}$. No cytotoxicity of the construct itself is another condition that needs to be fulfilled in order to achieve successful clinical translation of a nanomaterial. A modified LDH assay was developed $^{[48]}$ in order to avoid potential interferences that are often reported as a result of interfering interactions between carbonaceous nanomaterials and reagents in the colorimetric assays[76]. No difference in the cell survival after $24 \mathrm{~h}$ of treatment with increasing doses of empty or filled MWCNTs was observed comparing to the untreated cells (Figure 6a and 6b). The LDH assay data were validated using FACS (Figure $6 \mathrm{c}$ and $6 \mathrm{~d}$ ) by staining the cells treated with CNTs using cellular markers of apoptosis (Annexin V) and necrosis (Propidium Iodide). Cells exhibiting different responses to CNTs exposure were gated according to: healthy (unlabeled) cells (P18), early apoptotic (P19), late apoptotic and/or necrotic (P17) and necrotic cells (P16). Even at the highest dose of $100 \mu \mathrm{g} / \mathrm{mL}$, cells appeared unstained, indicating the presence of predominantly alive cells (more than $90 \%$ of counted cells appeared in this region; Figure S10). No significant cytotoxic responses compared to the untreated cells were observed for all tested doses (Figure S10). Overall, using two approaches (modified LDH and FACS) we confirmed that empty or MWCNTs filled with $\mathrm{NaI}$ or $\mathrm{GdCl}_{3}$ did not induce any significant cytotoxic response in the two cell lines and at the dose-escalation regime studied here. 
a)

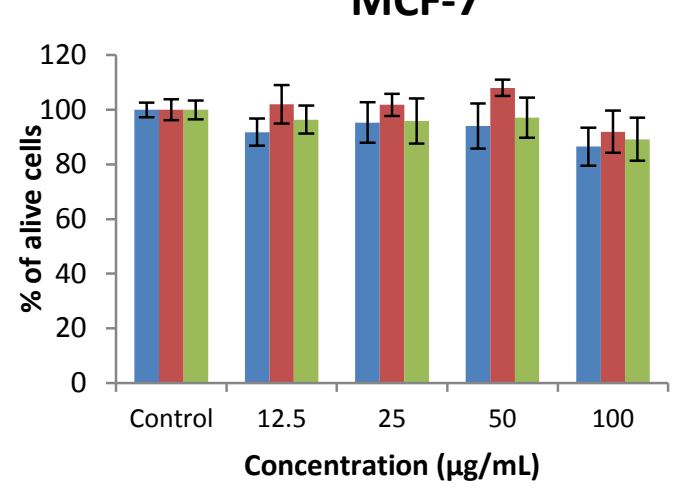

c)
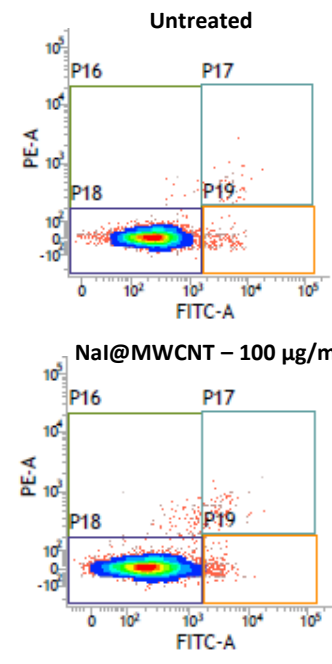

MCF-7
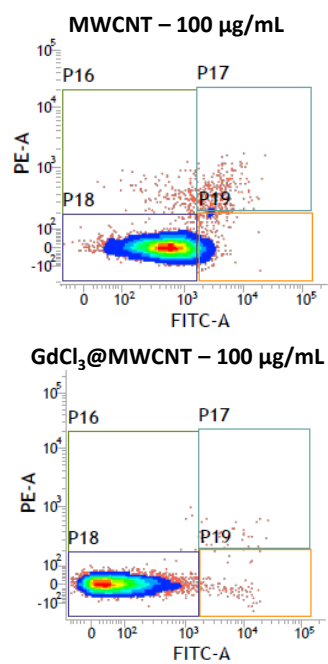

b)

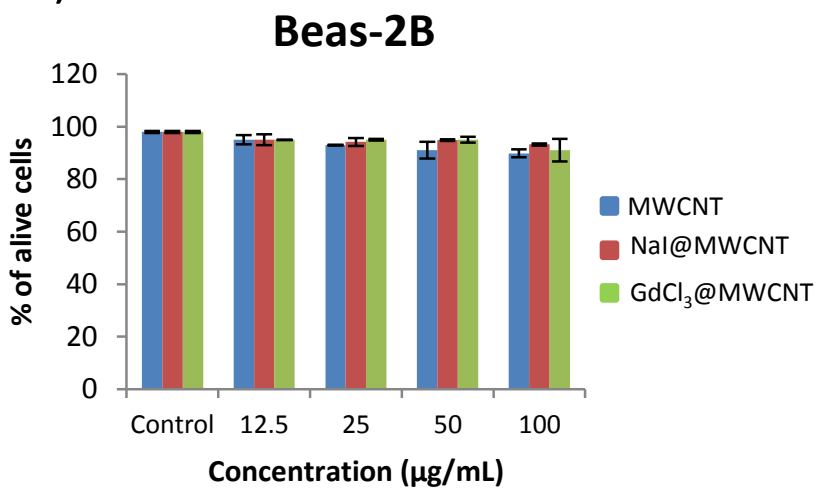

d)

Beas-2B
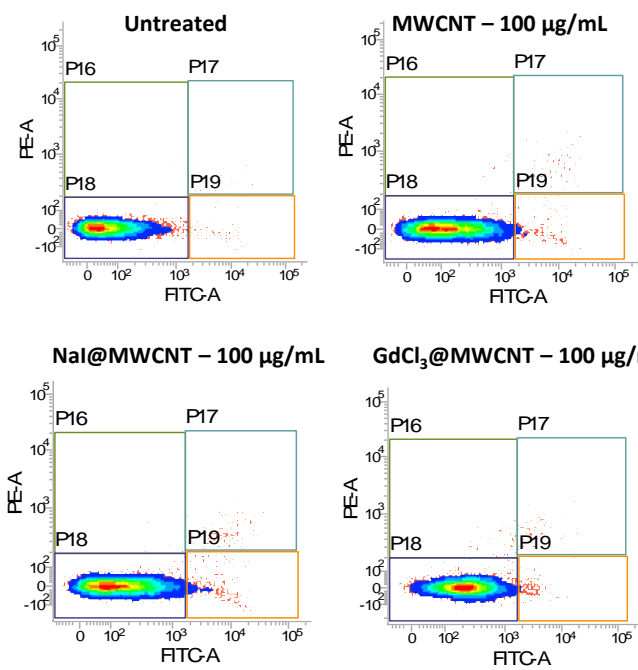

$\mathrm{GdCl}_{3} @ \mathrm{MWCNT}-100 \mu \mathrm{g} / \mathrm{mL}$

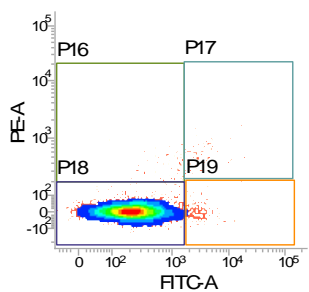

Figure 6. Cytotoxicity of empty or filled MWCNTs. a) and b) Assessment of the toxicity of the CNTs using modified LDH assay in MCF-7 and Beas-2B cells. Cells were treated at escalating doses of the material for $24 \mathrm{~h}$. Data are represented as mean $\pm \operatorname{SD}(n=6)$. c) and d) Assessment of the toxicity of the material by flow cytometry using PI/Annexin V staining after incubation with the material for $24 \mathrm{~h}$. Alive cells are represented in the P18 region on the plots, early apoptotic are represented in the P19 region, late apoptotic and/or necrotic cells are shown in P17 region and necrotic cells are found in the P16 region. Data are represented as mean \pm SD $(n=3)$. 


\section{Conclusions}

Filling and end-closing of multi-walled carbon nanotubes has been achieved in one-step by thermal annealing of open-ended carbon nanotubes in the presence of a chosen inorganic payload. This is a fast, simple and versatile approach that allows the formation of a wide variety of multi-walled carbon nanocapsules (closed-ended filled carbon nanotubes). BET, Raman, HAADF STEM and TEM analyses of the prepared materials suggest a spontaneous closure of the tips of MWCNTs to a certain extent after being annealed at or above $1000{ }^{\circ} \mathrm{C}$. Filling MWCNTs at $1200{ }^{\circ} \mathrm{C}$ turned out to be the most suitable temperature in preparing samples of closed-ended filled carbon nanotubes clean from external, non-encapsulated material. Once the MWCNTs are filled, the non-encapsulated compounds can be easily removed in a faster manner than when using SWCNTs, likely due to the lower bundling rate of MWCNTs. The present onepot filling and end-closing protocol is highly versatile, provided that the material to be encapsulated is stable in the molten state at this range of temperatures $\left(1000-1200{ }^{\circ} \mathrm{C}\right)$, and does not react with the carbon nanotubes. Several metal halides have been sealed in the cavities of CNTs in the present study, namely $\mathrm{NaI}, \mathrm{KI}, \mathrm{BaI}_{2}, \mathrm{GdCl}_{3}$ and $\mathrm{SmCl}_{3}$. These are interesting payloads for a variety of applications. For instance, the growth of individual layers of both $\mathrm{GdCl}_{3}$ and $\mathrm{SmCl}_{3}$ has been observed forming tubular van der Waals heterostructures. When an individual layer is seamlessly wrapped into a cylinder, the resulting single-walled nanotube combines the characteristics of both two-dimensional (2D) and one-dimensional (1D) materials. On the other hand, the encapsulated compounds also hold interest for the development of imaging and therapeutic agents. Biocompatibility of both empty and filled multi-walled carbon nanotubes was studied in vitro, showing that nanocapsules did not induce cellular death after 
being internalized by cells. We believe that the proposed one-pot strategy will boost the synthesis and applications of novel hybrid materials.

\section{Acknowledgements}

The research leading to these results has received funding from the People Programme (Marie Curie Actions) of the European Union's FP7 Programme under REA grant agreement n`290023 (RADDEL). We acknowledge financial support from Spanish Ministry of Economy and Competitiveness through the "Severo Ochoa" Programme for Centres of Excellence in R\&D (SEV-2015-0496, ICMAB; SEV-2013-0295, ICN2), and CHALENG (MAT2014-53500-R). The ICN2 is funded by the CERCA programme. We thank MATGAS facilities for providing access to TGA, especially Mar Estelles for helping with the equipment and Universitat de Barcelona for ICP, Raman and EA services. XPS data was acquired at the Laboratorio de Microscopías Avanzadas (LMA) - Instituto de Nanociencia de Aragón (INA).

\section{References}

[1] Wang R, Xie L, Hameed S, Wang C, Ying Y. Mechanisms and applications of carbon nanotubes in terahertz devices: A review. Carbon 2018;132:42-58.

[2] Sun L, Wang X, Wang Y, Zhang Q. Roles of carbon nanotubes in novel energy storage devices. Carbon 2017;122:462-74.

[3] Farrera C, Torres Andón F, Feliu N. Carbon Nanotubes as Optical Sensors in Biomedicine. ACS Nano 2017;11:10637-43. 
[4] Hart M, White ER, Chen J, McGilvery CM, Pickard CJ, Michaelides A, et al. Encapsulation and Polymerization of White Phosphorus Inside Single-Wall Carbon Nanotubes. Angew Chem Int Ed 2017;56:8144-8.

[5] Cabana L, Ballesteros B, Batista E, Magén C, Arenal R, Oró-Solé J, et al. Synthesis of $\mathrm{PbI}_{2}$ Single-Layered Inorganic Nanotubes Encapsulated Within Carbon Nanotubes. Adv Mater 2014;26:2016-21.

[6] Medeiros PVC, Marks S, Wynn JM, Vasylenko A, Ramasse QM, Quigley D, et al. Single-Atom Scale Structural Selectivity in Te Nanowires Encapsulated Inside Ultranarrow, Single-Walled Carbon Nanotubes. ACS Nano 2017;11:6178-85.

[7] Sandoval S, Kepic D, Perez del Pino A, Gyorgy E, Gomez A, Pfannmöller M, et al. Selective Laser-Assisted Synthesis of Tubular van der Waals Heterostructures of Single-Walled $\mathrm{PbI}_{2}$ within Carbon Nanotubes Exhibiting Carrier Photogeneration. ASC Nano 2018;12:664856.

[8] Agrawal KV, Shimizu S, Drahushuk LW, Kilcoyne D, Strano MS. Observation of extreme phase transition temperatures of water confined inside isolated carbon nanotubes. Nat Nanotechnol 2017;12:267.

[9] Kharlamova MV, Sauer M, Saito T, Sato Y, Suenaga K, Pichler T, et al. Doping of single-walled carbon nanotubes controlled via chemical transformation of encapsulated nickelocene. Nanoscale 2015;7:1383-91.

[10] Kharlamova MV. Advances in tailoring the electronic properties of single-walled carbon nanotubes. Progress in Materials Science 2016;77:125-211. 
[11] Chimowa G, Tshabalala ZP, Akande AA, Bepete G, Mwakikunga B, Ray SS, et al. Improving methane gas sensing properties of multi-walled carbon nanotubes by vanadium oxide filling. Sens Actuator B-Chem 2017;247:11-8.

[12] Jin F, Xiao S, Lu L, Wang Y. Efficient Activation of High-Loading Sulfur by Small CNTs Confined Inside a Large CNT for High-Capacity and High-Rate Lithium-Sulfur Batteries. Nano Lett 2016;16:440-7.

[13] Chuvilin A, Bichoutskaia E, Gimenez-Lopez MC, Chamberlain TW, Rance GA, Kuganathan N, et al. Self-assembly of a sulphur-terminated graphene nanoribbon within a singlewalled carbon nanotube. Nat Mater 2011;10:687.

[14] Chernov AI, Fedotov PV, Talyzin AV, Suarez Lopez I, Anoshkin IV, Nasibulin AG, et al. Optical Properties of Graphene Nanoribbons Encapsulated in Single-Walled Carbon Nanotubes. ACS Nano 2013;7:6346-53.

[15] Perivoliotis DK, Tagmatarchis N. Recent advancements in metal-based hybrid electrocatalysts supported on graphene and related 2D materials for the oxygen reduction reaction. Carbon 2017;118:493-510.

[16] Li H, Shi Y, Li L-J. Synthesis and optoelectronic applications of graphene/transition metal dichalcogenides flat-pack assembly. Carbon 2018;127:602-10.

[17] Wang Z, Li H, Liu Z, Shi Z, Lu J, Suenaga K, et al. Mixed Low-Dimensional Nanomaterial: 2D Ultranarrow $\mathrm{MoS}_{2}$ Inorganic Nanoribbons Encapsulated in Quasi-1D Carbon Nanotubes. J Am Chem Soc 2010;132:13840-7.

[18] Botos A, Biskupek J, Chamberlain TW, Rance GA, Stoppiello CT, Sloan J, et al. Carbon Nanotubes as Electrically Active Nanoreactors for Multi-Step Inorganic Synthesis: Sequential 
Transformations of Molecules to Nanoclusters and Nanoclusters to Nanoribbons. J Am Chem Soc 2016;138:8175-83.

[19] Sandoval S, Pach E, Ballesteros B, Tobias G. Encapsulation of two-dimensional materials inside carbon nanotubes: Towards an enhanced synthesis of single-layered metal halides. Carbon 2017;123:129-34.

[20] Ashokkumar AE, Enyashin AN, Deepak FL. Single Walled BiI 3 Nanotubes Encapsulated within Carbon Nanotubes. Scientific Reports 2018;8:10133.

[21] Heister E, Brunner EW, Dieckmann GR, Jurewicz I, Dalton AB. Are Carbon Nanotubes a Natural Solution? Applications in Biology and Medicine. ACS Appl Mater Interfaces 2013;5:1870-91.

[22] Serpell CJ, Kostarelos K, Davis BG. Can Carbon Nanotubes Deliver on Their Promise in Biology? Harnessing Unique Properties for Unparalleled Applications. ACS Central Sci 2016;2:190-200.

[23] Battigelli A, Ménard-Moyon C, Da Ros T, Prato M, Bianco A. Endowing carbon nanotubes with biological and biomedical properties by chemical modifications. Adv Drug Deliv Rev 2013;65:1899-920.

[24] Hong G, Diao S, Antaris AL, Dai H. Carbon Nanomaterials for Biological Imaging and Nanomedicinal Therapy. Chem Rev 2015;115:10816-906.

[25] Tran LA, Hernández-Rivera M, Berlin AN, Zheng Y, Sampaio L, Bové C, et al. The use of gadolinium-carbon nanostructures to magnetically enhance stem cell retention for cellular cardiomyoplasty. Biomaterials 2014;35:720-6.

[26] Meike van der Zande, Balaji Sitharaman, X. Frank Walboomers, Lesa Tran, Jeyarama S. Ananta, Andor Veltien, et al. In Vivo Magnetic Resonance Imaging of the Distribution Pattern of 
Gadonanotubes Released from a Degrading Poly(Lactic-Co-Glycolic Acid) Scaffold. Tissue Eng C: Methods 2010;17.

[27] Liu X, Marangon I, Melinte G, Wilhelm C, Ménard-Moyon C, Pichon BP, et al. Design of Covalently Functionalized Carbon Nanotubes Filled with Metal Oxide Nanoparticles for Imaging, Therapy, and Magnetic Manipulation. ACS Nano 2014;8:11290-304.

[28] Shao L, Lin T-W, Tobias G, Green MLH. A simple method for the containment and purification of filled open-ended single wall carbon nanotubes using $\mathrm{C}_{60}$ molecules. Chem Commun 2008:2164-6.

[29] Ge H, Riss PJ, Mirabello V, Calatayud DG, Flower SE, Arrowsmith RL, et al. Behavior of Supramolecular Assemblies of Radiometal-Filled and Fluorescent Carbon Nanocapsules InVitro and In-Vivo. Chem 2017;3:437-60.

[30] Fidiani E, Costa PMFJ, Wolter AUB, Maier D, Buechner B, Hampel S. Magnetically Active and Coated Gadolinium-Filled Carbon Nanotubes. J Phys Chem C 2013;117:16725-33.

[31] Lu C, Sandoval S, Puig T, Obradors X, Tobias G, Ros J, et al. Novel Fe $3 \mathrm{O}_{4} @ G N F @ \mathrm{SiO}_{2}$ nanocapsules fabricated through the combination of an in situ formation method and $\mathrm{SiO}_{2}$ coating process for magnetic resonance imaging. RSC Advances 2017;7:24690-7.

[32] Satishkumar BC, Govindaraj A, Mofokeng J, Subbanna GN, Rao CNR. Novel experiments with carbon nanotubes: opening, filling, closing and functionalizing nanotubes. J Phys B-At Mol Opt Phys 1996;29:4925.

[33] Eder D. Carbon Nanotube-Inorganic Hybrids. Chem Rev 2010;110:1348-85.

[34] Vilatela JJ, Eder D. Nanocarbon Composites and Hybrids in Sustainability: A Review. ChemSusChem 2012;5:456-78. 
[35] Shearer CJ, Cherevan A, Eder D. Application and Future Challenges of Functional Nanocarbon Hybrids. Adv Mater 2014;26:2295-318.

[36] Hong SY, Tobias G, Al-Jamal KT, Ballesteros B, Ali-Boucetta H, Lozano-Perez S, et al. Filled and glycosylated carbon nanotubes for in vivo radioemitter localization and imaging. Nat Mater 2010;9:485-90.

[37] Shao L, Tobias G, Huh Y, Green MLH. Reversible filling of single walled carbon nanotubes opened by alkali hydroxides. Carbon 2006;44:2855-8.

[38] Spinato C, Perez Ruiz de Garibay A, Kierkowicz M, Pach E, Martincic M, Klippstein R, et al. Design of antibody-functionalized carbon nanotubes filled with radioactivable metals towards a targeted anticancer therapy. Nanoscale 2016;8:12626-38.

[39] Serpell CJ, Rutte RN, Geraki K, Pach E, Martincic M, Kierkowicz M, et al. Carbon nanotubes allow capture of krypton, barium and lead for multichannel biological X-ray fluorescence imaging. Nat Commun 2016;7:13118.

[40] Sceats EL, Green JC, Reich S. Theoretical study of the molecular and electronic structure of one-dimensional crystals of potassium iodide and composites formed upon intercalation in single-walled carbon nanotubes. Phys Rev B 2006;73:125441.

[41] Law JJ, Guven A, Wilson LJ. Relaxivity enhancement of aquated Tris( $\beta$ diketonate)gadolinium(III) chelates by confinement within ultrashort single-walled carbon nanotubes. Contrast Media Mol Imaging 2014;9:409-12.

[42] Harris AL, Veale CR. Polymorphism in gadolinium trichloride. J Inorg Nucl Chem $1965 ; 27: 1437-9$. 
[43] Winter A, George A, Neumann C, Tang Z, Mohn MJ, Biskupek J, et al. Lateral heterostructures of two-dimensional materials by electron-beam induced stitching. Carbon 2018;128:106-16.

[44] Zhou B, Wang X, Dong S, Zhang K, Mi W. Tunable gap opening and spin polarization of two dimensional graphene/hafnene van der Waals heterostructures. Carbon 2017;120:121-7.

[45] Kierkowicz M, Pach E, Santidrián A, Sandoval S, Gonçalves G, Tobías-Rossell E, et al. Comparative study of shortening and cutting strategies of single-walled and multi-walled carbon nanotubes assessed by scanning electron microscopy. Carbon 2018;139:1-11.

[46] Cabana L, Bourgognon M, Wang JT-W, Protti A, Klippstein R, de Rosales RTM, et al. The Shortening of MWNT-SPION Hybrids by Steam Treatment Improves Their Magnetic Resonance Imaging Properties in vitro and in vivo. Small 2016;12:2893-905.

[47] Zhu W, von dem Bussche A, Yi X, Qiu Y, Wang Z, Weston P, et al. Nanomechanical mechanism for lipid bilayer damage induced by carbon nanotubes confined in intracellular vesicles. Proceedings of the National Academy of Sciences 2016;113:12374-9.

[48] Ali-Boucetta H, Al-Jamal KT, Kostarelos K. Cytotoxic assessment of carbon nanotube interaction with cell cultures. Methods Mol Biol 2011;726:299-312.

[49] Tobias G, Shao L, Salzmann CG, Huh Y, Green MLH. Purification and Opening of Carbon Nanotubes Using Steam. J Phys Chem B 2006;110:22318-22.

[50] Pumera M, Miyahara Y. What amount of metallic impurities in carbon nanotubes is small enough not to dominate their redox properties? Nanoscale 2009;1:260-5.

[51] Batchelor-McAuley C, Wildgoose GG, Compton RG, Shao L, Green MLH. Copper oxide nanoparticle impurities are responsible for the electroanalytical detection of glucose seen using multiwalled carbon nanotubes. Sens Actuator B-Chem 2008;132:356-60. 
[52] Kagan VE, Tyurina YY, Tyurin VA, Konduru NV, Potapovich AI, Osipov AN, et al. Direct and indirect effects of single walled carbon nanotubes on RAW 264.7 macrophages: Role of iron. Toxicol Lett 2006;165:88-100.

[53] Shvedova A, Castranova V, Kisin E, Schwegler-Berry D, Murray A, Gandelsman V, et al. Exposure to Carbon Nanotube Material: Assessment of Nanotube Cytotoxicity using Human Keratinocyte Cells. J Toxicol Env Health Part A 2003;66:1909-26.

[54] Pulskamp K, Diabaté S, Krug HF. Carbon nanotubes show no sign of acute toxicity but induce intracellular reactive oxygen species in dependence on contaminants. Toxicol Lett 2007;168:58-74.

[55] Kolodiazhnyi T, Pumera M. Towards an Ultrasensitive Method for the Determination of Metal Impurities in Carbon Nanotubes. Small 2008;4:1476-84.

[56] Geng HZ, Zhang XB, Mao SH, Kleinhammes A, Shimoda H, Wu Y, et al. Opening and closing of single-wall carbon nanotubes. Chem Phys Lett 2004;399:109-13.

[57] Brunauer S, Emmett PH, Teller E. Adsorption of Gases in Multimolecular Layers. J Am Chem Soc 1938;60:309-19.

[58] Gauden P, Terzyk A, Furmaniak S, Wiśniewski M, Kowalczyk P, Bielicka A, et al. Porosity of closed carbon nanotubes compressed using hydraulic pressure. Adsorption 2013;19:785-93.

[59] Cabana L, Ke X, Kepić D, Oro-Solé J, Tobías-Rossell E, Van Tendeloo G, et al. The role of steam treatment on the structure, purity and length distribution of multi-walled carbon nanotubes. Carbon 2015;93:1059-67. 
[60] Ballesteros B, Tobias G, Shao L, Pellicer E, Nogués J, Mendoza E, et al. Steam Purification for the Removal of Graphitic Shells Coating Catalytic Particles and the Shortening of Single-Walled Carbon Nanotubes. Small 2008;4:1501-6.

[61] Mazzoni MSC, Chacham H, Ordejón P, Sánchez-Portal D, Soler JM, Artacho E. Energetics of the oxidation and opening of a carbon nanotube. Physical Review B 1999;60:R2208-R11.

[62] Briggs D, Grant JT. Surface Analysis by Auger and X-ray Photoelectron Spectroscopy. Chichester, United Kingdom: IM Publications 2003.

[63] Ferrari AC. Raman spectroscopy of graphene and graphite: Disorder, electron-phonon coupling, doping and nonadiabatic effects. Solid State Communications 2007;143:47-57.

[64] Ballesteros B, Tobias G, Ward MAH, Green MLH. Quantitative Assessment of the Amount of Material Encapsulated in Filled Carbon Nanotubes. J Phys Chem C 2009;113:2653-6. [65] Martincic M, Pach E, Ballesteros B, Tobias G. Quantitative monitoring of the removal of non-encapsulated material external to filled carbon nanotube samples. Physical Chemistry Chemical Physics 2015;17:31662-9.

[66] Kierkowicz M, González-Domínguez JM, Pach E, Sandoval S, Ballesteros B, Da Ros T, et al. Filling Single-Walled Carbon Nanotubes with Lutetium Chloride: A Sustainable Production of Nanocapsules Free of Nonencapsulated Material. ACS Sustain Chem Eng 2017;5:2501-8.

[67] Nie C, Galibert A-M, Soula B, Flahaut E, Sloan J, Monthioux M. A new insight on the mechanisms of filling closed carbon nanotubes with molten metal iodides. Carbon 2016;110:4850. 
[68] Anumol EA, Enyashin AN, Batra NM, Costa PMFJ, Deepak FL. Structural and chemical analysis of gadolinium halides encapsulated within $\mathrm{WS}_{2}$ nanotubes. Nanoscale 2016;8:12170-81. [69] Teo WZ, Khim Chng EL, Sofer Z, Pumera M. Cytotoxicity of halogenated graphenes. Nanoscale 2014;6:1173-80.

[70] Kostarelos K, Lacerda L, Pastorin G, Wu W, Wieckowski S, Luangsivilay J, et al. Cellular uptake of functionalized carbon nanotubes is independent of functional group and cell type. Nat Nanotechnol 2007;2:108-13.

[71] Pantarotto D, Singh R, McCarthy D, Erhardt M, Briand JP, Prato M, et al. Functionalized carbon nanotubes for plasmid DNA gene delivery. Angew Chem Int Ed 2004;43:5242-6.

[72] Marangon I, Boggetto N, Ménard-Moyon C, Venturelli E, Béoutis ML, Péchoux C, et al. Intercellular carbon nanotube translocation assessed by flow cytometry imaging. Nano Lett 2012;12:4830-7.

[73] Marangon I, Boggetto N, Ménard-Moyon C, Luciani N, Wilhelm C, Bianco A, et al. Localization and relative quantification of carbon nanotubes in cells with multispectral imaging flow cytometry. J Vis Exp 2013:e50566.

[74] Vranic S, Boggetto N, Contremoulins V, Mornet S, Reinhardt N, Marano F, et al. Deciphering the mechanisms of cellular uptake of engineered nanoparticles by accurate evaluation of internalization using imaging flow cytometry. Part Fibre Toxicol 2013;10:2.

[75] Vranic S, Gosens I, Jacobsen NR, Jensen KA, Bokkers B, Kermanizadeh A, et al. Impact of serum as a dispersion agent for in vitro and in vivo toxicological assessments of $\mathrm{TiO}_{2}$ nanoparticles. Arch Toxicol 2016.

[76] Wörle-Knirsch JM, Pulskamp K, Krug HF. Oops They Did It Again! Carbon Nanotubes Hoax Scientists in Viability Assays. Nano Lett 2006;6:1261-8. 